\title{
Gereformeerde Theologie in
}

\section{Zuid-Afrika}

DS K. H. DE GROOT

\section{NAAR EEN NIEUWE THEOLOGISCHE OPLEIDING?}

Het is slecht gesteld met de theologische opleiding in Zuid-Afrika. Tenminste, als men mensen als de bekende ds. Boesak mag geloven. In een interview met het opinie-weekblad "De Tijd" (van 23 mei 1986) zegt hij het volgende over zijn verblijf in ons land: "Ik heb in Holland heel veel geleerd. Ik ontdekte, hoe weinig ik wist, hoe hopeloos onze eigen theologie studie in Zuid-Afrika was en in veel gevallen nog steeds is. Ik ontdekte, hoe kwalijk het is, als theologie en kerk dienstbaar gemaakt worden aan een onderdrukkende ideologie. Ik ontdekte hier pas, wat voor gevolgen apartheid heeft voor de kerk en de theologie in Zuid-Afrika. Kampen (Boesak bedoe!t de Theologische Hogeschool van de Gereformeerde kerken in Nederland) opende mijn ogen en deed mij ontdekken, hoe opwindend theologie kan zijn en hoe heel anders dan de stenen-voor-brood, die de blanke "sendelinge" mij op de theologische hogeschool van de N.G. Sendingkerk aanreikten. Ik leerde anders om te gaan met de Schrift en met de theologie en ik begreep beter, wat bedoeld wordt met "gereformeerde theologie", de theologie, waar de blanke Calvinistische Afrikaners zo trots op zijn, waar ze zo veel over praten en zo weinig van weten".

Met dit citaat zitten wij meteen in heel de problematiek, waarin Gereformeerd kerkelijk Zuid-Afrika verkeert. Onder "Gereformeerd" versta ik de drie kerken van Gereformeerde oorsprong: de Nederduits Hervormde, de Nederduits Gereformeerde kerk en de Gereformeerde kerke van Suid-Afrika, vaak kortweg aangeduid als de "Dopperkerken". Boesak behoort tot de N.G. Sendingkerk, de "kleurlingdochter" van de blanke N.G. kerk. Zo ziet hij dus zijn eigen theologische opleiding in Zuid-Afrika. Daar kreeg hij stenen voor brood. Maar in Nederland, aan de hogeschool in Kampen, ging het licht voor hem op. Hij promoveerde daar in 1976 op een proefschrift, getiteld: Afscheid van de onschuld. Volgens zijn eigen zeggen was dit ook het einde van de "naïeve kleurling-dominee, die in 1970 naar Kampen kwam". Hij leerde daar anders om te gaan met de Schrift en met de theologie. Ik denk, dat de kernkwestie ligt bij dat punt van het "anders omgaan met de Schrift". Daar kom ik straks nog op terug.

Eerst wil ik nog een andere zwarte theoloog aanhalen, die op ongeveer dezelfde lijn zit. Het is ds. L. W. Mazamisa, die in het blad van de Theologische Hogeschool te Kampen (nr. 1, 1986) een artikel schreef over: Kampen en Zuid-Afrika. We krijgen dan nog meer informatie, die cok dieper gaat. Hij stelt de vraag, waarom het voor 
zwarte theologen noodzakelijk was om naar Kampen te komen, voor verdere studie. Hij noemt daarvoor drie redenen.

In de eerste plaats: de theologische vorming van de zwarte kerken wordt overheerst door theologen van de N.G. kerk. Daardoor is het onmogelijk, de theologie en de methoden daarvan, die gebaseerd zijn op culturele vooronderstellingen van blanke theologie, verbonden met de blanke maatschappij en de blanke waarden en normen, te verwerpen.

In de tweede plaats is er in de theologische opleidingen in ZuidAfrika geen mogelijkheid om theologie te bedrijven, waarvan sociale analyse en theologische bezinning deel uitmaken. (Even een tussenopmerking: de uitdrukking "sociale analyse" wijst in een zeer bepaalde richting. Vooral ook, als hij spreekt over de deelname aan de strijd en de hoop van de onderdrukte belijdende gemeenschap.)

In de derde plaats noemt hij, dat in de raciaal en ethnisch gescheiden theologische opleiding de student gezien wordt als een theolo gische puber. Allerlei voorschriften zijn vastgesteld voor zijn gedrag, b.v. ook op het gebied van de kleding. Hij werpt de vraag op, waarom er zo ' $n$ groot verschil is tussen blanke en zwarte theologen, die beiden in Kampen gestudeerd hebben. Volgens Mazamisa zit het voornaamste verschil in de benadering. Als zwarte theologen in Nederland komen, dan houden $\mathrm{zij}$ op met een theologisch proces, dat onkritisch en onnadenkend is. $\mathrm{Zij}$ aanvaarden nieuwe denkwijzen, die het hun mogelijk maken een theologie op te bouwen, die dialogisch en creatief is. Op deze werkwijze, die men dan in Kampen leert, kom ik straks terug.

Tenslotte schrijft Mazamisa, dat een eigen theologische opleiding noodzakelijk is. Daar kunnen dan als docenten optreden de theologen, die in Kampen en aan de V.U. gestudeerd hebben. Het is niet onduidelijk, in welke richting deze opleiding zal gaan. Een voorbeeld daarvan hebben we reeds in het Kairosdocument. Dat wordt genoemd een bijdrage van de wetenschappelijke theologie aan een heldere formulering van de belijdenis. Daarmee wordt bedoeld de belijdenis van een bloedende en stervende gemeenschap.

Zo wordt de situatie in Zuid-Afrika getekend.

$\mathrm{Bij}$ deze opleiding van zwarte theologen (waarvan men droomt) zal de theologie van de bevrijding de allesbeheersende rol spelen. Alles zal staan in het teken daarvan. Daarmee zal de Gereformeerde theologie afgedaan hebben. Die gaf immers stenen voor brood, vol gens Boesak? Die is toch helemaal blanke theologie, met de blanke waarden en normen, volgens Mazamisa? In Zuid-Afrika komt dan een zwarte theologie, met de daaraan verbonden maatschappij en de waarden en normen daarvan. Wat zullen die inhouden? Zal men de Europese versie van de bevrijdingstheologie overnemen? Als het Kairosdocument de beheersende richtlijn is, dan zal dat zeker het geval zijn. Maar het is de vraag, of dat zal gebeuren. Het genoemde document ademt toch nog te veel de Europese geest.

Er klinken ook heel andere geluiden, onder de zwarte theologen in Zuid-Afrika! Het is nodig om eerst hierbij stil te staan. Dat is nodig, 
omdat de Gereformeerde theologie daar steeds meer mee in aanraking zal komen. Daar komt nog bij, dat die principes van de zwarte theologie niet tot Zuid-Afrika beperkt zijn. Wij krijgen ook steeds meer met deze principes te maken. Het ziet er naar uit, dat deze hoe langer hoe meer de theologie zullen gaan beheersen. Waar gaat het nu over in de "zwarte theologie"?

\section{HET ONTSTAAN VAN DE ZWARTE THEOLOGIE.}

Om dat goed te zien, moeten we ons eerst afvragen, hoe deze theologie ontstaan is. Daarvoor moeten we naar Noord-Amerika, de Verenigde Staten. Daar behoort één tiende deel van de bevolking tot de negers. Ze zijn daar in de vorige eeuw (of nog eerder) als slaven naar toe gebracht. Ook landgenoten hebben zich daaraan bezondigd en zijn met schepen vol negers de Oceaan overgestoken. Velen stierven onderweg, want de schepen zaten volgepakt. In de vorige eeuw is in Amerika de slavernij afgeschaft. Zo werden de negers vrij!

Dat betekende niet, dat zij daarmee in de praktijk gelijke rechten met de blanken kregen. Vanaf het begin van deze eeuw is er een felle strijd gevoerd, voor deze rechten. Eerst werd die strijd ge weldloos gevoerd. Aan de protestoptochten, die gehouden werden, is de naam van ds. Martin Luther King verbonden.'In 1965 komt dan de wet op het kiesrecht, ook voor de negers. Zij woonden vooral in de Zuidelijke staten. Daarmee was de zaak nog lang niet voor elkaar. Blanke en zwarte strijders voor het kiesrecht werden vermoord. Dan staan er figuren op, die zeggen: Zie je wel, dat je door geweldloze acties niets bereikt? Wij moeten overgaan tot het gebruiken van geweld. Zo ontstaat de Black-Power-beweging, die oproept tot onmiddellijke revolutionaire actie. Vooral jongeren voelen zich daardoor aangesproken. Maar deze beweging mist nog een geestelijke achtergrond. Die wordt geleverd door de Black Theology. Het is niet vreemd, dat de theologie hiermee in verband gebracht wordt. Onder de negers zijn vele Christenen en zij willen dit in één lijn zien met hun geloof. Hun leiders laten zich daardoor ook inspireren.

Wat wil men nu? Wat is de opzet, het doel van deze zwarte macht, verbonden met de zwarte theologie?

De algehele bevrijding van de gekleurde mensen, dat ze van de blanke onderdrukking verlost worden. Dat moet dan gebeuren met alle middelen, die maar nodig zijn. Deze gedachte van bevrijding wordt verbonden met het Christelijk geloof en wel op een bepaalde manier. Het evangelie van Christus voor deze tijd is, dat Hij Zich totaal gelijk maakt aan de armen en de onderdrukten. Jezus was Zelf ook arm. Hij had geen enkel bezit; $\mathrm{Hij}$ had geen plaats om het hoofd neer te leggen. Hij was geboren in een stal. De machthebbers van $\mathrm{Zijn}$ tijd wilden niets van Hem weten. Toen $\mathrm{Hij}$ te lastig werd voor hen, hebben ze Hem ter dood gebracht.

Zwarten maken nu hetzelfde door en daarom kan Jezus hen zo goed begrijpen. Ja, nog meer: $\mathrm{Hij}$ is solidair met hen. Dat is een heel ander evangelie, dan wat de zwarte kerkleden totnogtoe gehoord 
hadden. Het was vaak zo, dat men elkaar troostte met de toekomst. Dan zou alle discriminatie, alle armoede en ellende verdwijnen. In de hemel zouden zij het volle geluk ontvangen. Denkt $u$ maar aan de vele negerliederen, die deze toekomst bezingen. De zwarte kerken hadden er zo zelf aan meegewerkt, dat de status-quo gehandhaafd werd. Met status-quo bedoel ik de toestand, zoals die totnogtoe was, dat de blanken het voor het zeggen hadden. Dat moet nu radicaal veranderen.

$Z_{0}$ 'n evangelie van de toekomst staat helemaal buiten deze tijd. Nú moet er bevrijding komen. Niet in de hemel, na dit leven, maar hier en nu. Daar moet de kerk en daar moet de theologie op gericht zijn. Die theologie heeft het er lelijk bij laten zitten. Ze is voorbij gegaan aan de armoede en de verdrukking of ze heeft zich daarbij neergelegd. De theologen zaten in hun ivoren torens, maar ze begaven zich niet in de ellende van het grondvlak. De kerk heeft al te vaak de regeringen of de machthebbers gesteund, doordat ze de mensen opriep tot onderwerping aan de overheid. Nu zegt de blanke theologie wel, dat ze alle aandacht wil richten op deze tjid en de noden daarvan. Maar zij gaat aan de slavernij van de zwarten voorbij, want in de grond van de zaak zijn zij nog steeds slaven. Daarom is er een zwarte theologie nodig.

\section{HET DOEL VAN DE ZWARTE THEOLOGIE}

Het evangelie moet van z'n "blankheid" bevrijd worden. Wat bete. kent dit? Alle Christelijke leerstukken moeten zó verklaard worden, dat ze echt iets te zeggen hebben tot de zwarten, in hun situatie van onderdrukking. Als het bij voorbeeld gaat over de schepping, dan moet er alle nadruk op vallen, dat alle mensen gelijk geschapen zijn, met gelijke rechten. Als het gaat over Christus, dan moet $\mathrm{Hij}$ niet in de eerste plaats verkondigd worden als de Middelaar, dic: stierf voor onze zonden. Hij moet gepredikt worden als de Bevrijder die de zwarten uit hun ellende van armoede en onderdrukking haalt. Alles moet in het teken van die bevrijding staan! Niet van de zonde, zoals die steeds door de blanke theologie op de voorgrond is geschoven.

Het gaat niet om een geestelijke bevrijding, maar om een totale, van heel het leven, hier en nu! Deze bevrijding moet door revolutie, door geweld tot stand gebracht worden. Waarom is dat nodig?

Kun je niet proberen door vreedzame middelen tot verandering te komen? Het gaat niet om oppervlakkige verbeteringen, terwijl het systeem intact blijft. Heel de maatschappij moet radicaal veranderd worden. Dat kan alleen door een revolutie, door het gebruiken van geweld. De machthebbers zitten stevig in het zadel. $\mathrm{Zij}$ gebruiken geweld om hun positie, koste wat het kost, te handhaven. Ze willen wel enige concessies doen, als het beslist niet anders kan. Maar verder gaan ze niet. Om die reden is geweld nodig. Dit alles geldt (en gold!) niet alleen voor Noord-Amerika. Het geldt evenzo voor Zuid-Amerika. Daar heb je in de meeste landen bevrijdingsbewegingen, die dit tot stand willen brengen. Wij kunnen dit ook toepassen op Zuid-Afrika. Heel de zwarte theologie beweegt zich binnen deze kaders. 


\section{NAAR EEN EIGEN AFRIKAANSE ZWARTE THEOLOGIE}

Wat Zuid-Afrika betreft, komt daar nog iets bij. Ik heb hiermee de Afrikanisering van de theologie op het oog. We kunnen ook zeggen: de zwarte theologie, in een Afrikaanse vorm. Wat bedoelt men daarmee? Daarvoor moeten we even naar de hedendaagse theologie gaan. Daar kun je de zwarte theologie niet van losmaken. Die staat helemaal onder invloed van de moderne theologische wetenschap. De moderne theologie zegt, dat wij niet moeten afgaan op wat het Nieuwe Testament ons leert over Jezus Christus. Waarom is dat niet mogelijk? Omdat wij in de evangelieën en de brieven een bepaalde verwerking van het echte evangelie vinden. Het wordt daarin pasklaar gemaakt voor de Grieks-Romeinse wereld van die tijd. Het is nu de taak van de theologie om dat Grieks-Romeinse er af te halen. Dan kom je bij Jezus Christus, zoals Hij werkelijk geweest is. Om een beeld te gebruiken: in oude kerken vind je geregeld wandschilderingen terug. Die worden bij een restauratie ontdekt. Vaak waren die overgeschilderd en zo verdwenen. Maar als je die lagen er af haalt, dan komt de oorspronkelijke schildering weer te voorschijn. Zo moet je ook doen met het beeld van Jezus Christus in het Nieuwe Testament. Dan komt de echte Christus te voorschijn en wel als de grote Bevrijder! Hij is het antwoord op de vraag naar bevrijding, die zo sterk bij de zwarten leeft.

Maar als eens het evangelie in een Grieks-Romeinse gewaad verscheen, dan mag het nu in een Afrikaans gewaad verschijnen. Dat is zelfs nodig!

Het evangelie is immers de boodschap van God voor de mens in zijn gegeven situatie. Dan alleen spreekt het de mensen aan en heeft het betekenis voor hen. Maar de mens, die in een bepaalde situatie leeft, kun je nooit losmaken van heel zijn achtergrond. Dat is de traditionele cultuur in Zuid-Afrika. De waarde daarvan moet opnieuw erkend worden.

Door de blanken is steeds benadrukt, dat dié cultuur minderwaardig is. Die moest dan ook vervangen worden door de Westerse cultuur. Dan pas zouden de zwarten gelukkig kunnen zijn. Maar de zwarte moet zich weer bewust worden van de waarde van zijn eigen cultuur.

\section{TWEE STROMINGEN IN DE AFRIKANISERENDE THEOLOGIE}

$\mathrm{Nu}$ zijn er op dit punt twee stromingen, die in een tegengestelde richting gaan. De één zegt: de traditionele cultuur is wezenlijk identiek met de Westerse. Zo kun je die beiden met elkaar ver. zoenen, omdat ze gelijkwaardig zijn. Daarin ligt opgesloten, dat je de traditionele godsdienst van Afrika kunt verzoenen met het Christendom. In de praktijk kom je dit syncretisme (dat is de samensmelting van heidendom en Christendom) heel veel tegen. Er zijn miljoenen zwarte Christenen, die zo leven. Ik denk b.v. aan de Zionisten, ons welbekend uit de verslagen van de zendelingen. De andere stroming staat hier lijnrecht tegenover. Die is van mening, dat de eigen Afrikaanse cultuur ver boven de Westerse staat. Die is nu juist minderwaardig! Deze instelling wordt bevorderd door de afwijzende houding tegenover alle bevoogding. De zwarten la- 
ten zich niet meer als onmondige kinderen behandelen en zelfs niet als mensen, die op hetzelde niveau staan. Nee, zwart is beter dan blank!

Wat hebben de blanken niet allemaal voor kwaad gedaan? Zij hebben twee wereldoorlogen ontketend. $\mathrm{Zij}$ hebben andere landen en volken eeuwenlang overheerst. Er zouden nog wel vele andere wandaden van de blanken opgesomd kunnen worden.

Tegen heel deze achtergrond moeten we nu de Gereformeerde theologie in Zuid-Afrika zien. Met heel deze ontwikkeling krijgt ze steeds meer te maken. Dat is een heel gevaarlijke ontwikkeling, want de grondslagen van het Christelijk geloof staan hierbij op het spel.

\section{WAAR EEN AFRIKAANSE THEOLOGIE OP UITLOOPT}

In 1973 verscheen er een bundel opstellen (die in het Nederlands vertaald werd), getiteld: Zwarte theologie in Zuid-Afrika. De oorspronkelijke uitgave droeg als titel: Black Theology, the South African voice. Daarin vinden we de volgende uitspraken: De klassieke theologische methode van het Westen, waar wij bijna allemaal onder geleden hebben (denk even aan de eerder aangehaalde woorden van Boesak) bestond erin een gedegen en gedétailleerde akademische studie te maken van de belangrijkste bronnen van de Christelijke leer, om, zo zei men ons, Gods Zelfopenbaring te onderzoeken. De klassieke bronnen waren dan de Bijbel, de traditie en de rede. Zo hebben wij in onze theologische opleiding met Bijbelstudie te maken gekregen.

Wij hebben de inhoud bestudeerd, de problemen rond de schrijvers van de Bijbelboeken en rond de datering. We hebben de technieken geleerd van de historische kritiek, van vorm- en bronnenkritiek om zo de teksten open te leggen (a.w., p. 27). Maar de problemen van het dagelijkse leven van ons vo!k hadden we nauwelijks overdacht. Hierbij moeten wij twee vragen stellen (volgens het genoemde boek): wat is onze Afrikaanse erfenis? Hoe was het, voordat de blanken kwamen met hun God en ons leven als heidens en onzedelijk veroordeelden? De tweede vraag is: hoe is dit anders geworden door de blanke invloed? (a.w., p. 28).

We voelen wel aan, wat er achter deze vragen ligt, n.l. het zich be roepen op de traditionele cultuur. In deze cultuur had men b.v. bepaalde ideeën over het gezag. Dat is heel anders dan wat de blanken zich hierbij voorstellen. Zij denken daarbij aan autoriteit, je wil aan anderen opleggen, desnoods met geweld. Het is de machtswellust, die hen beheerst. De blanken zeggen, dat hun God ook zo is, dat Hij over ons heerst, dat Hij ons Zijn wil oplegt. Maar de zwarte theologie moet een heel ander Godsbeeld vormen, dat zich aansluit bij de ideeën van de zwarten (a.w., p. 31). Een passend symbool voor dit Godsbegrip zou zijn: God is vrijheid (a.w., p. 32). Vervolgens wordt dan erkend, dat die Bijbel dat gezag van God wel duidelijk laat zien, reeds in het verhaal van Adam en Eva. God kondigt een absoluut verbod af en de mens moet daaraan zonder meer gehoorzamen. Als hij dat niet doet, dan zal hij met de dood gestraft worden (a.w., p. 42). Verder wordt God getekend als 
een mannelijk persoon en als behorend tot het blanke ras. Zo wor den Hij en Christus ook steeds afgebeeld (a.w., p. 43). Dat wordt nog versterkt, doordat God Vader genoemd en Christus zijn Zoon. Dat zijn ook weer echt mannelijke woorden (p. 44). Maar deze beelden van God, als de grote Vaderfiguur en van Christus als de liefhebbende Zoon in ons midden, moeten verdwijnen (p. 48). Er moeten nieuwe beelden van God komen, zoals: God is liefde. Waar liefde gekend, gevoeld en getoond wordt, wordt God ervaren en geopenbaard (p. 49). Of: God is de vrijheid, die geopenbaard werd in onze geschiedenis (p. 49).

De zendelingen echter hebben de mensen in de war gebracht met hun nieuwe godsdienst (p. 64). Zij hebben hen bang gemaakt met verhalen over de hel. $\mathrm{Zij}$ schilderen hun God af als een veeleisende God, die vereerd wilde worden. Wie dat niet deed, zou zwaar gestraft worden. Deze koude, wrede godsdienst was de inheemse bevolking vreemd. Toen deze aanvaard werd, gingen daarmee de zwarte, culturele waarden te gronde (p. 64). Het is nu de tak van alle zwarte priesters en predikanten om het Christendom te redden. Dat kan alleen, als ze de benadering van de zwarte theologie overnemen (p. 65).

\section{DE GEREFORMEERDE THEOLOGIE IN ZUID-AFRIKA}

Dit is nu de situatie, waarmee de Gereformeerde theologie steeds meer in aanraking komt. Is het nu werkelijk daar zo slecht mee gesteld, als ds. Boesak opmerkte? Die indruk heb ik niet gekregen, toen ik in mei 1986 een bezoek van drie weken aan Zuid-Afrika bracht. In het kader hiervan bezocht ik de theologische opleidingen in Pretoria (N.G. kerk), Hammanskraal, Potchefstroom en Stellenbosch. Naast de informatie, die ik daar kreeg, ga ik vooral af op de studiegidsen van de bovengenoemde opleidingen, die van Hammanskraal uitgezonderd. Daar kon met mij niet zo 'n studiegids verschaffen. Wel kon ik een aantal gegevens vinden in de bundel, die uitgegeven werd bij het tienjarig bestaan van de genoemde theologische school. Deze bundel draagt als titel: Die saailand is die wêreld. In zulke studiegidsen vinden we een overzicht van rle studie gang zelf en van de literatuur, die gebruikt wordt. Daar kun je veel uit op maken.

In de eerste plaats is het opvallend, dat een behoorlijk deel van de studieboeken uit het Engelse taalgebied afkomstig is. Vroeger werd er vooral in Amerika ook al veel gepubliceerd op theologisch gebied, maar voor ons besef was het in de regel te oppervlakkig. Dat is veranderd en nu komen daar goede en diepgaande studies vandaan. Verder is er veel literatuur in het Afrikaans. Dit laat zien, dat er in Zuid-Afrika hard gestudeerd wordt. De boeken uit Nederland zijn teruggedrongen. Ze zijn er nog wel, maar niet meer zo veel als voorheen. De reden daarvoor zal zijn, dat Nederland z'n goede Gereformeerde naam grotendeels heeft verloren. Vooral de V.U. en de Theologische Hogeschool in Kampen namen in vroegere jaren een belangrijke plaats in. Heelwat studenten trokken daarheen, voor verdere studie. Dat is beëindigd, door verschillende oorzaken. De banden met de Gereformeerde (Synodale) kerken wer- 
den verbroken. Ook beschouwde men in Zuid-Afrika de V.U. en Kampen als centra van revolutionaire theologie, waar blanke studenten niet langer veilig waren. Deze laatste opmerking las ik in het blad van de Hogeschool te Kampen (nr. 1, 1986). Die komt dus niet uit Zuid-Afrikaanse kring!

Wij mogen er dankbaar voor zijn, dat er in Zuid Afrika nog echt een Gereformeerde theologie is waarin Gods Woord centraal staat. Van Schriftkritiek merk je weinig en helemaal niet in de Dopperkerken. Zo kunnen wij een goed gebruik maken van de boeken, die daar geschreven zijn. Het heeft nog als bijkomend voordeel, dat ze geschreven zijn in een taal, die dicht bij het Nederlands staat. Opvallend vond ik in Potchefstroom, dat er zo 'n sterke nadruk gelegd werd op de geschiedenis van de openbaring. In alle vier studiejaren wordt daar aandacht aan besteed. Ik vernam, dat dit mede te danken is aan de werken van K. Schilder en vooral van B. Ho!werda. Dit kan ook een goed tegenwicht bieden aan de zwarte theologie. Daar wordt de Bijbel op een bepaalde manier gebruikt. H. J. Schilder heeft eens heel de bevrijdingstheologie (daartoe behoort ook de zwarte theologie) en haar gebruik van de Schrift met de term "modern exemplarisme" getypeerd (zie daarvoor Joh. Francke, De jonaste theologie, Groningen, 1975, p. $145 \mathrm{vv}$.). Die term betekent: de Bijbel levert hoofdzakelijk voorbeelden, waar mensen iets mee kunnen doen. Het gaat echter om de geschiedenis van het heil, dat in Jezus Christus naar ons is toegekomen.

\section{WAT WIJ KUNNEN LEREN VAN DE GEREFORMEERDE THEOLOGIE IN ZUID-AFRIKA}

Ook op dit punt kunnen we wel iets leren van Zuid-Afrika, want het heilshistorische is bij ons te veel op de achtergrond geraakt. We zullen meer dan ooit moeten teruggaan op de Bijbel. Dat is altijd gebeurd in de Gereformeerde kerken, kan iemand opmerken. Dat was wel de opzet. Maar ons lezen van de Schrift is vaak beinvloed door dogmatische stellingen. Of het gebeurde vooral vanuit een praktische achtergrond. Ik bedoel daarmee, dat je iets las in de Schrift en het meteen naar jezelf toehaalde, zonder je af te vragen, wat het nu precies bedoelde te zeggen. Achteraf zag je dan in, dat de tekst een andere richting wees. Vooral ook was er het gevaar om bepaalde teksten op zichzelf te plaatsen en niet te letten op heel het verband. Maar het grootste gevaar is wel, als je niet meer spreekt vanuit de Schrift, maar vanuit de situatie. Dat is een tendens, die steeds meer naar voren komt. Bij voorbeeld bij de Kampense hogeschool van de Gereformeerde kerken. Ongeveer een jaar geleden kon men in de krant lezen, dat die hogeschool een bredere opzet van de opleiding wilde.

Een naieve lezer zou kunnen denken, dat men zich meer wilde wij den aan de kennis van de Bijbel en van de Gereformeerde belijdenis. Die kennis was bij vele studenten klein, zoals op classisexamens herhaaldelijk bleek. Maar dat was niet de bedoeling! Er moet meer aandacht gegeven worden aan de huidige situatie en aan andere godsdiensten en levensbeschouwingen. Om verontrusten gerust te stellen, voegde men er meteen aan toe, dat niet bedoeld werd een 
alternatief voor de huidige opleiding te geven, die nog op de oude Gereformeerde beginselen en methoden is gegrond. Maar het centrale punt in de theologie moet zijn de plaats van het Christelijk geloof in de huidige samenleving, volgens genoemd krantenartikel. Wie enigzins op de hoogte is met de theologische ontwikkelingen, weet wel, wat daarmee bedoeld wordt. De Bijbel en de uitleg daarvan, de Gereformeerde geloofsleer en ethiek staan niet meer op de voorgrond. Het gaat om de huidige samenleving; die moet je goed kennen en analiseren. Vandaar de grote aandacht voor andere godsdiensten en vooral ook voor de sociologie. De maatschappij moet eerst als het ware doorgelicht worden. Dan pas wordt duidelijk, wat de Bijbel nog in deze maatschappij te zeggen heeft. Daar zal dan ook de prediking op afgestemd moeten worden. Zo gaat de wereld een duchtig woord meespreken.

In Zuid-Afrika is dat de Afrikaanse wereld, die nieuwe godsbeelden nodig heeft, volgens de zwarte theologie. In ons land is dat heel de Westerse wereld, die even zeer op zoek is naar zulke godsbeelden, die de moderne mens aanspreken. Wat is het tweede gebod dan nog altijd actueel!

Tegenover heel dit gedachtenklimaat weten wij ons verbonden met de Gereformeerde kerken in Zuid-Afrika en de beoefening van de theologie daar. Van die goede, Schriftuurlijke wetenschap kunnen wij veel leren en misschien ook nog van elkaar leren. Wij hebben in ons land weer een eigen kerkelijke en ook theologische ontwikkeling doorgemaakt. Daarin kan het Seminarie een belangrijke rol spelen, als het dit goede naar zich toetrekt. Het is tenslotte dezelfde strijd, die wij te voeren hebben. Het is een strijd tegen een machtige theologische wereld, die zich vaak ook met andere machten verbindt. Maar wij mogen het enige effectieve wapen in die strijd bezitten, n.l. het zwaard van de Heilige Geest, het Woord van God. Laten wij dat zwaard dan ook goed gebruiken! Laten we ons samen in het gebruik daarvan oefenen, tot bewaring van Christus gemeente, in Zuid Afrika en hier!

Naschrift: Bovenstaande is een enigzins omgewerkte versie van een referaot, dat gehouden werd op de siudiedag van het Nederlands Gereformeerde Seminarium, gevestigd te Zaandam, op 25 October 1986. Dit Seminariun gaat uit van een Stichting, die ondersteund wordt door een aantal Nederlands Gereformeerde gemeentien. Dese opleiding tot de Dienst des Woords wordi verzorgd door een aantal predikanten uit bovengenoemde kerken. Deze studiedag was voral bedoeld voor allen, die belangstelling hebben voor het werk van dit Seminarie. 